\title{
Ubiquitin C-terminal Hydrolase L1 Regulates Lipid Raft-dependent Endocytosis
}

\author{
Seo-Jun Kang ${ }^{1,2,3 \dagger}$, Jin Soo Kim ${ }^{1,2 \dagger}$ and Sang Myun Park ${ }^{1,2,3 *}$ \\ ${ }^{1}$ Department of Pharmacology, Ajou University School of Medicine, Suwon 16499, ${ }^{2}$ Chronic Inflammatory Disease Research \\ Center, Ajou University School of Medicine, Suwon 16499, ${ }^{3}$ BK21 plus program, Department of Biological Sciences, Ajou \\ University School of Medicine, Suwon 16499, Korea
}

Ubiquitin C-terminal hydrolase L1 (UCH-L1) is a deubiquitinating enzyme that is highly expressed in neurons, and gathering evidence indicates that UCH-L1 may play pathogenic roles in many neurodegenerative disorders such as Alzheimer's disease and Parkinson's disease (PD). Additionally, lipid rafts have attracted interest in neurodegeneration as playing a common role in many neurodegenerative diseases. In the present study, we demonstrated that UCH-L1 associates with lipid rafts as with other PD-associated gene products. In addition, UCH-L1 regulates lipid raft-dependent endocytosis and it is not dependent on the expression and degradation of caveolin-1 or flotillin-1. Finally, UCH-L1 regulates cell-to-cell transmission of $\alpha$-synuclein. This study provides evidence that many PD-associated gene products share common signaling pathways to explain the pathogenesis of PD.

Key words: alpha-synuclein, UCH-L1, Parkinson’s disease, prion disease

\section{INTRODUCTION}

Ubiquitin C-terminal hydrolase L1 (UCH-L1) is a deubiquitinating enzyme that is highly expressed in neurons, comprising $1 \sim 2 \%$ of total neuronal proteins [1]. Accumulating evidence indicates that UCH-L1 may be involved in the pathogenesis of many neurodegenerative disorders such as Alzheimer's disease (AD) and Parkinson's disease (PD). UCH-L1 is detected in cortical Lewy bodies and neurofibrillary tangles in patients with diffuse Lewy body disease and AD, respectively [2]. Down-regulation and extensive oxidative modification of UCH-L1 have been observed in the brains of AD and PD patients [3]. A missense mutation, I93M,

Received May 8,2018, Revised September 17,2018, Accepted September 18, 2018

\footnotetext{
* To whom correspondence should be addressed. TEL: 82-31-219-5063, FAX: 82-31-219-5069 e-mail:sangmyun@ajou.ac.kr

"These authors contributed equally to this work.
}

in UCH-L1 has been identified in patients with autosomal dominant familial PD [4], and an S18Y mutation in UCH-L1 has been reported to exert a neuroprotective effect against PD [5], although these genetic studies are controversial $[6,7]$.

Recently, lipid rafts have attracted interest in neurodegeneration. Lipid rafts are specialized membrane microdomains that are enriched in cholesterol and glycosphingolipids. They serve as platforms for the assembly of signaling molecules and regulate receptor-mediated signal transduction and endocytosis $[8,9]$. Changes in lipid rafts content are present in many neurodegenerative diseases such as AD, PD, Huntington's disease (HD), amyotrophic lateral sclerosis (ALS), and prion disease [10]. Also, significant alteration in numerous proteins in lipid rafts has been reported in $\mathrm{AD}$ and ALS mouse models $[11,12]$. A $\beta, \alpha$-synuclein, mutant huntingtin and prion, which are key players of $\mathrm{AD}, \mathrm{PD}, \mathrm{HD}$ and prion disease, respectively, have been found in lipid rafts [13-16] and the main proteins responsible for $A \beta$ generation such as amyloid precursor protein, $\beta$-secretase $[17,18]$, and presenilin-1 [19]
Copyright $\odot$ Experimental Neurobiology 2018. www.enjournal.org
This is an Open Access article distributed under the terms of the Creative Commons Attribution Non-Commercial License (http://creativecommons.org/licenses/by-nc/4.0) which permits unrestricted non-commercial use, distribution, and reproduction in any medium, provided the original work is properly cited. 
are present in lipid rafts. Many PD-associated gene products such as parkin, PINK1, DJ-1, and LRRK2 [20-23] also associates with lipid rafts, implying that lipid rafts may play a common role in many neurodegenerative diseases.

Additionally, recent evidence indicates that regional and intercellular spreading of tau and $\alpha$-synuclein are significant in the pathogenesis of $\mathrm{AD}$ and $\mathrm{PD}$, respectively. It has attracted much attention because intercellular spreading may explain unveiled pathogenesis and help with developing novel therapeutic interventions such as blocking secretion and reuptake [24, 25]. Previously, we demonstrated that $a$-synuclein is internalized into microglia in a lipid raft-dependent manner [26]. In addition, parkin, which has also been known to associate with lipid rafts, regulates caveolin-1 expression, which alters lipid rafts and the cell-to-cell transmission of a-synuclein [27], implying that lipid raft components may be involved in cell-to-cell transmission of a-synuclein.

Although UCH-L1 is mainly cytosolic protein, $20 \sim 50 \%$ of $\mathrm{UCH}-\mathrm{L1}$ is membrane-associated [28-30]. However, association of UCH-L1 with lipid rafts has not been explored. In the present study, we explored whether UCH-L1 associates with lipid rafts and whether altered UCH-L1 expression is involved in lipid raft function. Additionally, we explored the role of UCH-L1 in cell-tocell transmission of $\alpha$-synuclein.

\section{MATERIALS AND METHODS}

\section{Reagent and antibodies}

Antibodies against flotillin-1 and flotillin-2 were purchased from BD Bioscience (Fraklin Lakes, NJ, USA). Antibodies against GAPDH, CD71 (transferrin receptor) and UCH-L1 were purchased from Santa Cruz Biotechnology (Santa Cruz, CA, USA). Methyl- $\beta$-cyclodextrin and LDN-57444 were purchased from Sigma-Aldrich (St Louis, MO, USA). Rhodamine-conjugated transferrin and BOIPY ${ }^{\circledR}$ FL C5-Lactosylceramide were purchased from Molecular Probes (Leiden, the Netherlands).

\section{Cell culture and transfection}

SH-SY5Y, Hela, and human alpha-synuclein overexpressing SHSY5Y cells were grown in Dulbecco's modified Eagle's medium supplemented with $10 \%$ fetal bovine serum. Primary cortical neurons were cultured from Sprague-Dawley rat embryos at embryonic day 18 and maintained in Neurobasal medium (Invitrogen, Carlsbad, CA, USA) with L-glutamine and B-27 supplement (Invitrogen). Hela cells were transfected using lipofectamine 2000 (Invitorgen) according to the manufacturer's instruction. After 24 $\mathrm{hr}$ of transfection, the cells were used for further experiments. The plasmid for UCH-L1-myc was kindly provided by Prof. K. J. Lee at Ewha Womans University, Korea. UCH-L1 knockdown SHSY5Y cells were prepared using lentiviral constructs that expressed shRNA for UCH-L1 (Sigma-Aldrich) as described previously [31] and selected using puromycin.

\section{Western blot}

Cells were lysed in ice-cold RIPA buffer (50 mM Tris-HCl, pH 7.4, $150 \mathrm{mM} \mathrm{NaCl}, 0.25 \%$ sodium deoxycholate, $1 \%$ Triton X-100, $0.1 \%$ SDS and protease inhibitor mixture (GenDEPOT, Barker, TX)) for $20 \mathrm{~min}$ on ice after sonication for $3 \mathrm{~s}$. The lysates were cleared by centrifugation at $13,000 \times \mathrm{g}$ for $30 \mathrm{~min}$ at $4^{\circ} \mathrm{C}$. The supernatants were collected and mixed with sample buffer, resolved by SDS-PAGE, transferred to a nitrocellulose membrane and immunoblotted with the indicated antibodies. They were then detected using an enhanced chemiluminescence system (Thermo Fisher Scientific, Waltham, MA, USA).

\section{Isolation oflipid rafts}

Cell were washed three times with ice-cold phosphate-buffered saline (PBS) and lysed in ice-cold PBS containing 1\% Triton X-100 and protease inhibitor mixture. After the lysates were incubated for $10 \mathrm{~min}$ at $4^{\circ} \mathrm{C}$, they were centrifuged at $13,000 \times \mathrm{g}$ for $15 \mathrm{~min}$ at $4^{\circ} \mathrm{C}$. Supernatants were used as the soluble fraction. The pellets were washed with ice-cold PBS, solubilized with 1 x sample buffer and used as the insoluble fraction. These individual fractions were analyzed by SDS-PAGE and Western blot. For sucrose density gradient centrifugation fractionation analysis, cells were harvested in lysis buffer (25 mM MES, pH 6.5, $50 \mathrm{mM} \mathrm{NaCl}, 1$ $\mathrm{mM} \mathrm{Na}_{3} \mathrm{VO}_{4}$ and $1 \%$ Triton X-100) with protease inhibitor mixture and phosphatase inhibitor added, and incubated for $30 \mathrm{~min}$ at $4^{\circ} \mathrm{C}$ with Dounce homogenization every $10 \mathrm{~min}$. The lysates were adjusted to $42.5 \%$ sucrose, overlaid with 35 and 5\% sucrose in lysis buffer without Triton X-100. The mixed lysates were centrifuged at $275,000 \times \mathrm{g}$ for $20 \mathrm{hr}$ at $4^{\circ} \mathrm{C}$. From the top of the gradient, eleven $1-\mathrm{ml}$ fractions were collected, and some volumes of each fraction were analyzed by Western blot.

\section{Endocytosis assay}

Endocytosis assay was performed as described previously [22]. SH-SY5Y cells were incubated with 50 nM BOIPY ${ }^{\circledR}$ FL C5Lactosylceramide and $2.5 \mu \mathrm{g} / \mathrm{ml}$ rhodamine-conjugated transferrin for indicated times. The cells were then fixed and observed by confocal microscopy. The intensity was analyzed by ImageJ (http:// imagej.nih.gov/ij/).

\section{Cell-to-cell transmission assay using dual chamber}

Cell-to-cell transmission assay was performed as described pre- 
viously [27, 32]. a-Synuclein-overexpressing SH-SY5Y cells [26] as donor cells were differentiated by treatment with $50 \mu \mathrm{M}$ retinoic acid for 5 days. Then, SH-SY5Y cells cultured on coverslips on 12well plates as recipient cells were cocultured with differentiated a-synuclein-overexpressing SH-SY5Y cells cultured on the insert for $12 \mathrm{~h}$. The recipient cells were prepared for staining with the anti- $\boldsymbol{\alpha}$-syn antibody (BD Bioscience, Franklin Lakes, NJ, USA).

\section{Confocal microscopy}

Cells cultured on coverslips were washed twice with PBS and fixed in 4\% paraformaldehyde for $10 \mathrm{~min}$ at room temperature; the fixed cells were then washed with PBS and incubated with PBS containing $0.1 \%$ Triton X-100 for $10 \mathrm{~min}$ at room temperature. After they were washed with PBS, the cells were blocked with PBS containing $1 \%$ bovine serum albumin (GenDEPOT, Barker, TX, USA) for $1 \mathrm{hr}$ at room temperature, and then incubated overnight with primary antibodies at $4^{\circ} \mathrm{C}$. Preparations were then stained with fluorescence-conjugated secondary antibody (Jackson Im- munoresearch, West Grove, PA, USA) for $2 \mathrm{~h}$, mounted, and observed using a model LSM510 or LSM710 confocal microscope (Carl Zeiss, Jena, Germany).

\section{Statistical analysis}

All values are expressed as the mean \pm SEM. Statistical significance was evaluated using Graphpad Prism 5 (San Diego, CA, USA).

\section{RESULTS}

\section{UCH-L1 associates with lipid rafts}

To explore whether UCH-L1 associated with lipid rafts in the same way as other PD-associated proteins, we first isolated lipid rafts of SH-SY5Y cells based on their solubility in 1\% Triton X-100 on ice [33] and performed Western blot. As shown in Fig. 1A, we observed about $\sim 20 \%$ of total UCH-L1 in the cold Triton X-100 insoluble fraction, and we obtained similar results in the primary
A

SH-SY5Y
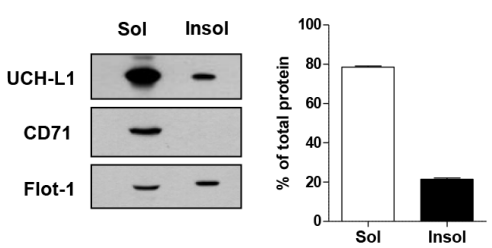

SH-SY5Y

D

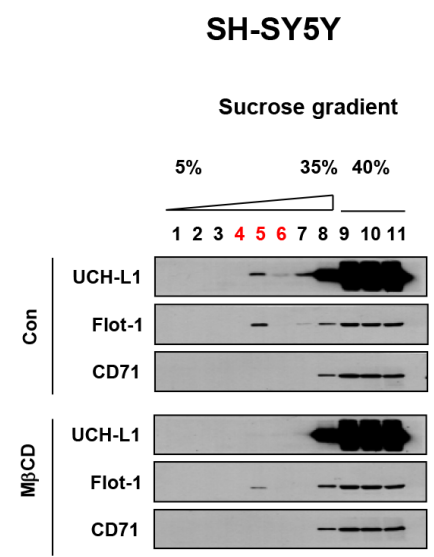

B

Primary neurons
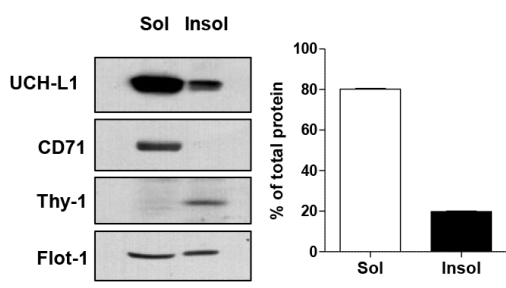

C
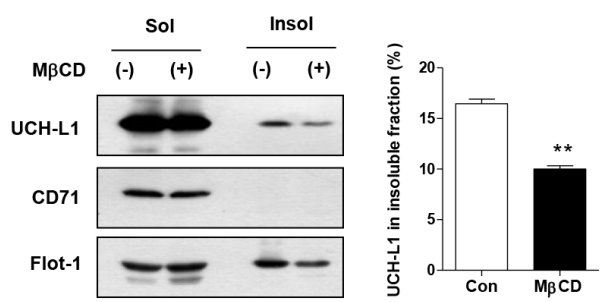

E

\section{Primary neurons}

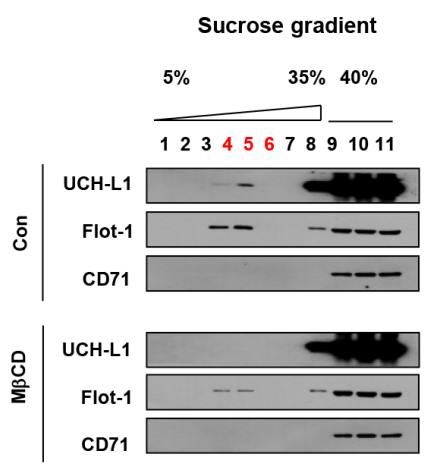

Fig. 1. UCH-L1 associates with lipid rafts. (A, B) SH-SY5Y cells (A) and rat primary neurons (B) were lysed in ice-cold 1\% Triton X-100 buffer and fractionated as soluble or insoluble fractions, and then the samples were analyzed by Western blot. (C) After the treatment of SH-SY5Y cells with 10 $\mathrm{mM} \mathrm{M} \beta C D$ for $1 \mathrm{~h}$, the cells were lysed in ice-cold 1\% Triton X-100 buffer and fractionated; the soluble and insoluble fractions were then analyzed by Western blot. Values obtained are from three independent experiments. ${ }^{*} \mathrm{p}<0.05,{ }^{* *} \mathrm{p}<0.01$ against control by unpaired t-test. (D, E) SH-SY5Y (D) and rat primary neurons (E) were fractionated by sucrose gradient centrifugation fractionation assay in the presence or absence of $10 \mathrm{mM} \mathrm{M} \beta \mathrm{CD}$, and the lysates were then analyzed by Western blot. 
neurons (Fig. 1B). When SH-SY5Y cells were treated with methyl$\beta$-cyclodextrin (M $\beta C D)$, a cholesterol-depleting agent, to exclude the possibility that UCH-L1 was isolated as a contaminant of lipid raft preparations [34], UCH-L1 was translocated into the Triton X-100 soluble fraction (Fig. 1C). To further confirm these observations, we isolated lipid rafts using sucrose density gradient centrifugation fractionation [22], and we also observed a small portion of UCH-L1 in the low-density lipid raft fractions (fractions \#4 \#6) of SH-SY5Y cells and primary neurons. Additionally, treatment with $\mathrm{M} \beta \mathrm{CD}$ induced the translocation of $\mathrm{UCH}-\mathrm{L} 1$ into non-lipid rafts fractions such as flotillin-1 (flot-1), a lipid raft marker (Fig.
$1 \mathrm{D}$ and $1 \mathrm{E}$ ), suggesting that $\mathrm{UCH}-\mathrm{L} 1$ associates with lipid rafts as a lipid raft protein and not as a contaminant.

\section{UCH-L1 regulates lipid raft-dependent endocytosis}

In our previous report, DJ-1, a PD-associated genes, associate with lipid rafts and regulates lipid raft-dependent endocytosis in astrocytes [22] by regulating flot-1 and caveolin-1 (cav-1) expression [35]. Parkin, which has been known to associate with lipid rafts [20], also regulates lipid raft-dependent endocytosis in MEF cells through regulating cav-1 expression [27]. To explore whether altered UCH-L1 expression was involved in lipid raft function, we
A

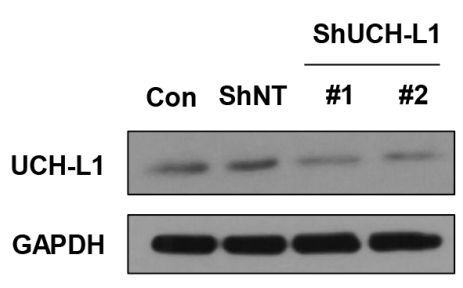

B

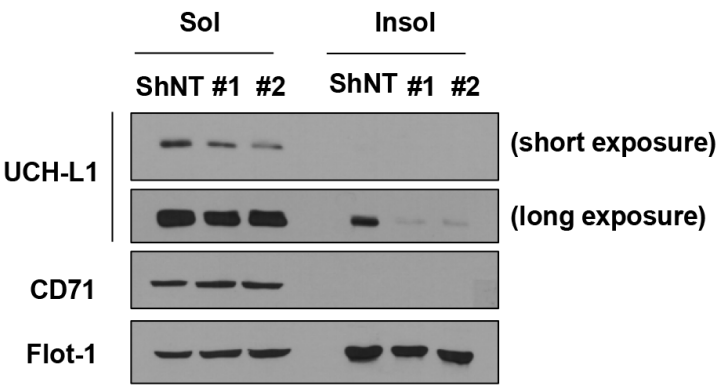

C

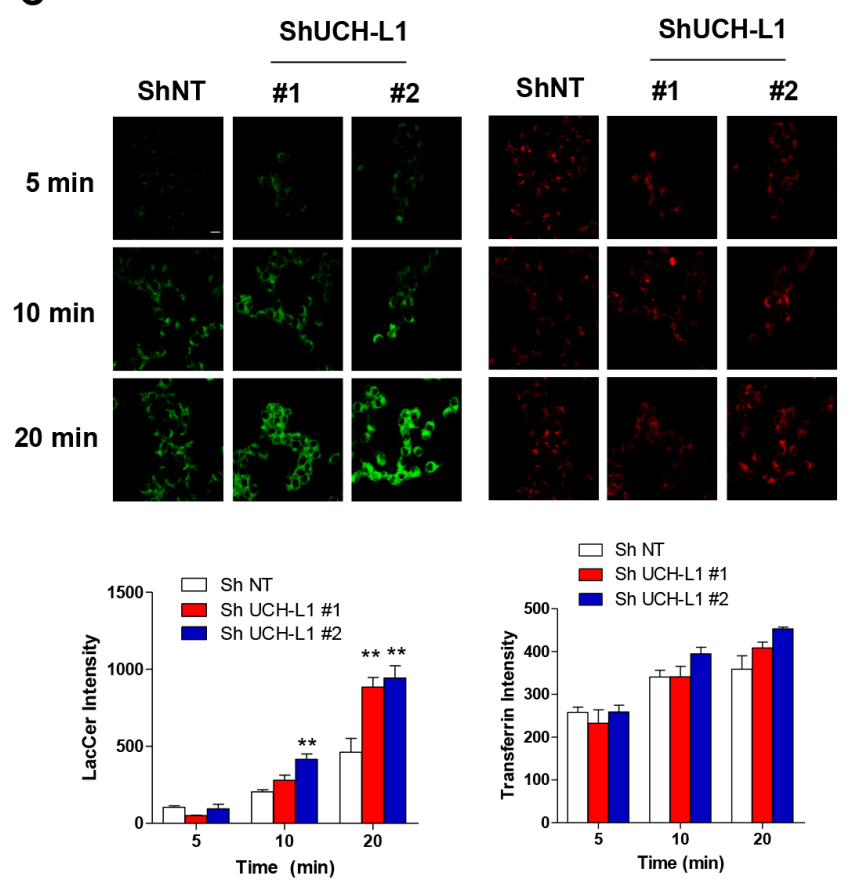

Fig. 2. UCH-L1 regulates lipid raft-dependent endocytosis. (A) Western blot was performed using lysates of NT and UCH-L1 KD \#1 and \#2 SH-SY5Y cells. (B) The cells were lysed in ice-cold 1\% Triton X-100 buffer and fractionated as soluble or insoluble fractions, and then the samples were analyzed by Western blot. (C) The cells were incubated with $50 \mathrm{nM}$ BOIPY ${ }^{\circledR}$ FL C5-Lactosylceramide and $2.5 \mu \mathrm{g} / \mathrm{ml}$ rhodamine-conjugated transferrin for the indicated times. (D) SH-SY5Y cells were treated with LDN-57444 for $24 \mathrm{~h}$, and then incubated with 50 nM BOIPY ${ }^{\circledR}$ FL C5-Lactosylceramide and 2.5 $\mu \mathrm{g} / \mathrm{ml}$ rhodamine-conjugated transferrin for the indicated times. The cells were then fixed and observed by confocal microscopy. The intensity was analyzed with the ImageJ program. Values are representative of three independent experiments. Scale bar indicates $20 \mu \mathrm{m}$. ${ }^{*} \mathrm{p}<0.05$, ${ }^{\star *} \mathrm{p}<0.01 \mathrm{against}$ control by one-way ANOVA. 
generated stable cell lines with downregulated UCH-L1 expression. UCH-L1 expression was efficiently downregulated in both fractions (Fig. 2A, B), and then performed general endocytosis assay using these cell lines. We used lactosylceramide as a marker for lipid raft-dependent endocytosis $[36,37]$ and transferrin as a marker for clathrin-dependent endocytosis [38, 39]. As shown in Fig. 2C, downregulation of UCH-L1 in SH-SY5Y cells enhanced lipid raft-dependent endocytosis, but not clathrin-dependent endocytosis. The treatment with LDN-57444, a UCH-L1 inhibitor that inhibits UCH-L1 hydrolase activity [40, 41], also enhanced lipid raft-dependent, but not clathrin-dependent endocytosis, suggesting that UCH-L1 regulates lipid raft-dependent endocytosis (Fig. 2D). Next, to explore whether UCH-L1 regulated lipid raftdependent endocytosis by regulating the expression of flot- 1 or cav-1 in the same way as DJ-1 or parkin, we performed Western blot analysis. We observed no changes in flot- 1 or -2 expression in UCH-L1 knock-down (KD) cell lines (Fig. 3A) or with LDN57444 treatment (Fig. 3B). Overexpression of UCH-L1 did not alter the expression of flot- 1 and cav-1 or -2 (Fig. 3C), suggesting that lipid raft-dependent endocytosis changes with $\mathrm{UCH}-\mathrm{L} 1$ do

A

ShUCH-L1

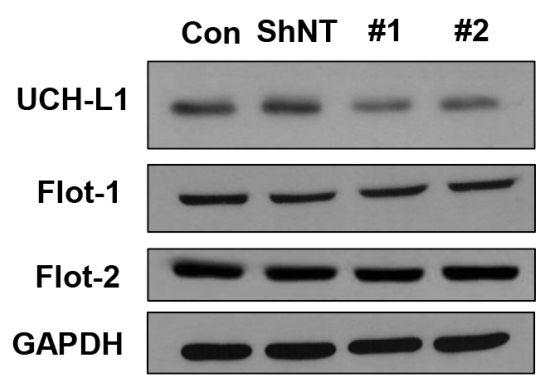

B

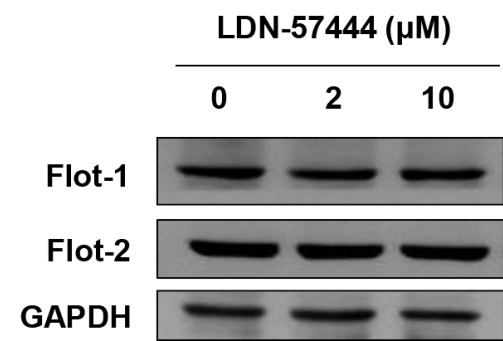

Flot-1

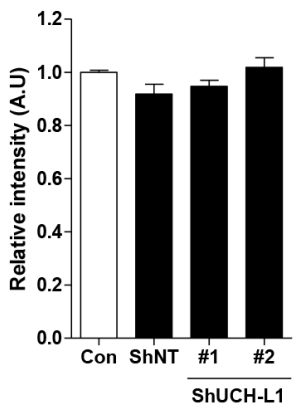

Flot-1

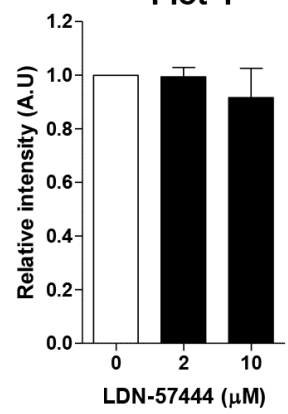

Flot-2

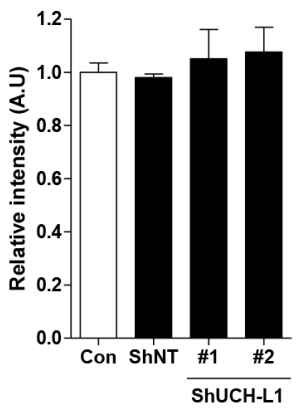

Flot-2

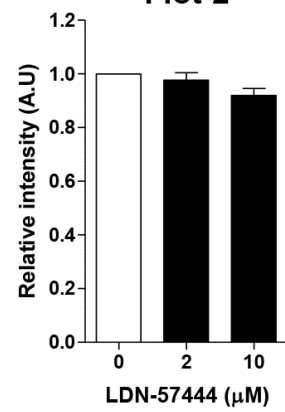

C

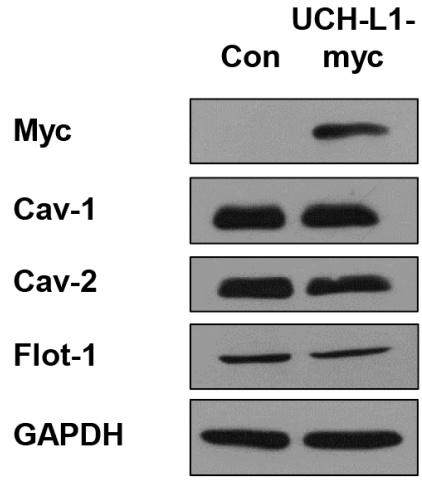

Cav-1

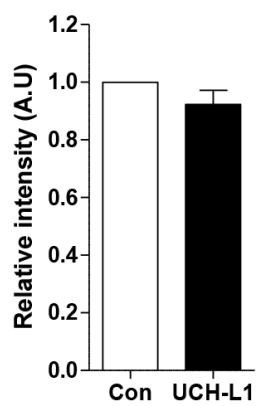

Cav-2

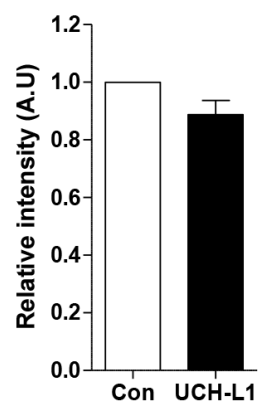

Flot-1

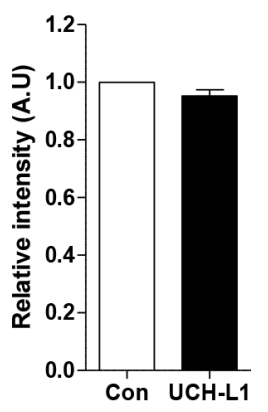

Fig. 3. UCH-L1 does not regulate the expression of caveolins and flotillins. (A) NT and UCH-L1 KD \# 1 and \#2 SH-SY5Y cells were lysed. (B) SH-SY5Y cells were treated with LDN 57444 for 24 h, and the cells were lysed. (C) Hela cells were transfected with myc-tagged UCH-L1, and the cells were lysed. The lysates were then analyzed by Western blot. Values obtained are from three independent experiments. 
not depend on the expression of flotillins and caveolins.

\section{UCH-L1 regulates cell-to-cell transmission of a-synuclein}

Previously, we demonstrated that extracellular $a$-synuclein is internalized into cells in a lipid raft-dependent manner [26], and also, signaling for lipid raft-dependent endocytosis is involved in cell-to-cell transmission of $\alpha$-synuclein [32]. Accordingly, we explored whether UCH-L1 regulates cell-to-cell transmission of a-synuclein. As shown in Fig. 4A, cell-to-cell transmission of a-synuclein was greater in UCH-L1 KD cell lines than in the controls. In addition, UCH-L1 inhibition by LDN-57444 treatment also enhanced cell-to-cell transmission of a-synuclein (Fig. 4B). Endogenous a-synuclein expression did not altered by downregulation of UCH-L1 (Fig. 4C). These data suggest that UCHL1 regulates cell-to-cell transmission of $\alpha$-synuclein via lipid raftdependent endocytosis.

\section{A}
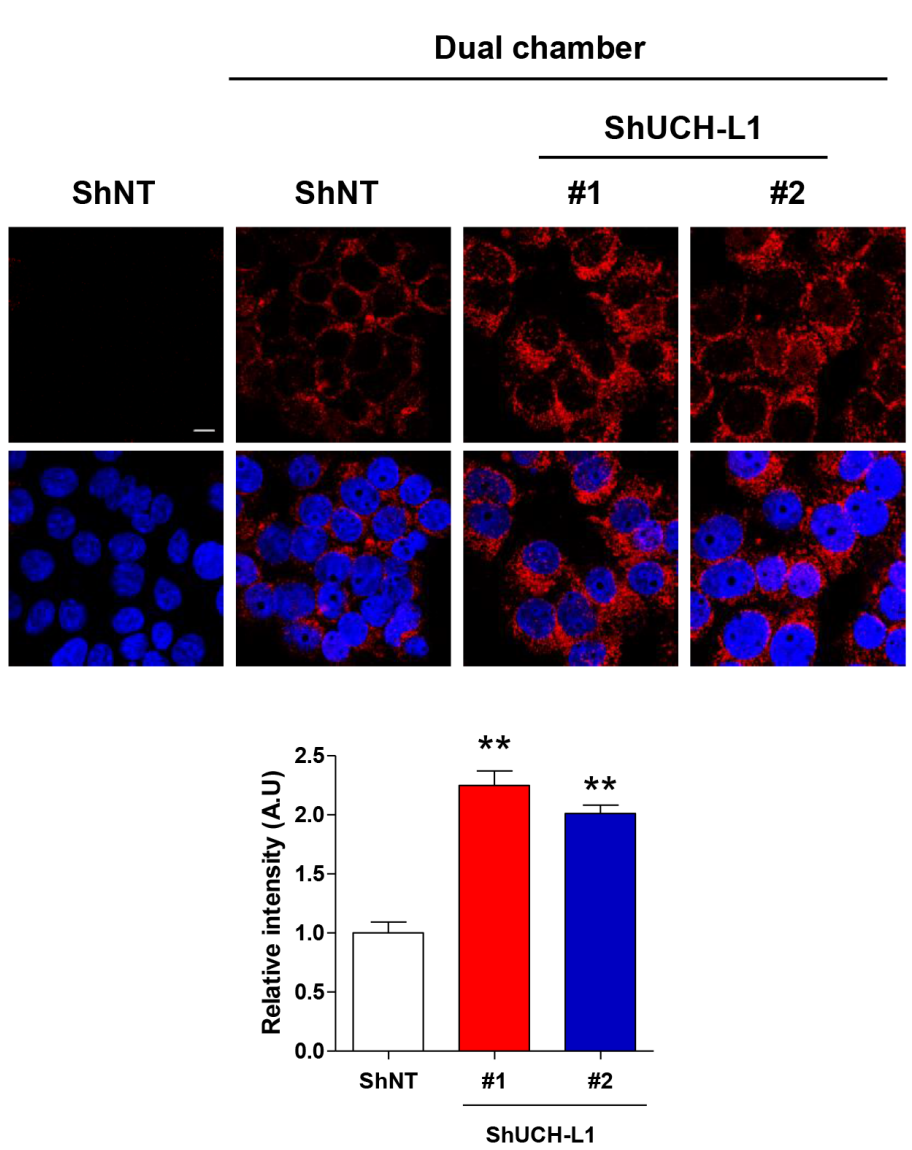

C

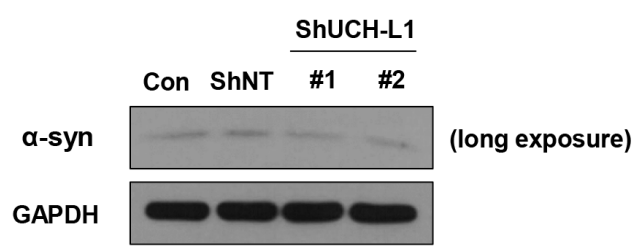

B

Dual chamber
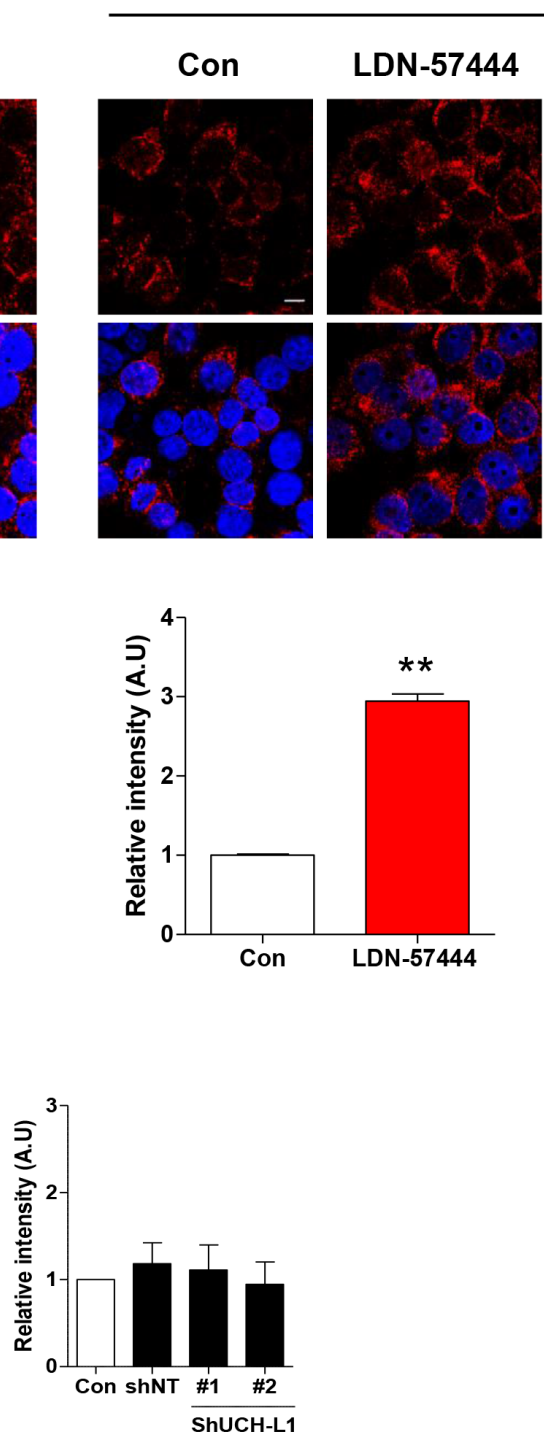

Fig. 4. UCH-L1 regulates cell-to-cell transmission of a-synuclein. (A) NT and UCH-L1 KD \#1 and \#2 SH-SY5Y cells were co-cultured with differentiated $a$-synuclein overexpressing SH-SY5Y cells for $12 \mathrm{hr}$ using dual chamber. (B) SH-SY5Y cells were treated with LDN-57444 for 24 h, and further co-cultured with differentiated $\alpha$-synuclein overexpressing SH-SY5Y cells for $12 \mathrm{hr}$ using dual chamber. The cells were then fixed and immunostained with the anti- $\alpha$-synuclein antibody. The intensity was analyzed with the ImageJ program. Values are representative of three independent experiments. ${ }^{*} \mathrm{p}<0.05,{ }^{* *} \mathrm{p}<0.01$ against control by one-way ANOVA (A) and unpaired t-test (B). (C) NT and UCH-L1 KD \# 1 and \#2 SH-SY5Y cells were lysed. The lysates were then analyzed by Western blot. Values obtained are from three independent experiments. 


\section{DISCUSSION}

The accumulating evidence indicates that the molecular pathways of neurodegeneration triggered by each mutation may be shared by several genetic forms of PD and may also play a role in the common sporadic disease [42-46]. Considering that the sublocalization of proteins is very important for protein function and that many PD-associated proteins, including a-synuclein, parkin, PINK1 and LRRK2, associate with lipid rafts, it is very informative to know whether other PD-associated proteins also associate with lipid rafts to elucidate the common molecular pathways involved in lipid rafts.

In the present study, we demonstrated that UCH-L1 also associates with lipid rafts. Lipid modifications of proteins such as palmitoylation and farnesylation facilitate the association of soluble proteins with cell membranes. Palmitoylation has been known to play important roles in trafficking into lipid rafts [47]; for instance, DJ-1 has been known to associate with lipid rafts via palmitoylation [22]. On the contrary, farnesylation drives membrane proteins to non-rafts domains [48], and UCH-L1 has been known to associate with membranes via farnesylation [30]. Nevertheless, UCH-L1 also associates with lipid rafts; FTI-277, a farnesylation inhibitor [49], and 2-bromopalmitate, a palmitoylation inhibitor [22] did not affect the association of UCH-L1 into lipid rafts (data not shown), suggesting that UCH-L1 associates with lipid rafts in palmitoylation- and farnesylation- independent manners, which is also supported by the finding that UCH-L1 membrane association is neuron specific and not dependent on farnesylation [50]. UCH-L1 also lacks obvious lipid interaction domains, but many deubiquitinases operate as part of larger protein complexes, which may induce the association of UCH-L1 with lipid rafts [1]. Farnesylated $\mathrm{H}$-ras also dynamically associates with lipid rafts by bound nucleotides, regulating downstream signals [51]. More studies will be needed to explore how $\mathrm{UCH}-\mathrm{L} 1$ associates with lipid rafts.

We also demonstrated that UCH-L1 regulates lipid raft-dependent endocytosis, but it is not dependent on the expression and degradation of caveolin-1 and flotillin-1, unlike DJ-1 and parkin. $\mathrm{UCH}-\mathrm{L} 1$ is intimately involved in regulating protein ubiquitination, which has emerged as a common element in the internalization of plasma membrane proteins. Cell surface turnover of GLT1 is mediated by ubiquitination [41], and ubiquitinated EGFR has been reported to be endocytosed through a lipid raft-dependent route [52]. Although we could not identify the exact substrates of $\mathrm{UCH}-\mathrm{L} 1$ for regulating lipid raft-dependent endocytosis, $\mathrm{UCH}-$ L1 may participate in lipid raft-dependent endocytosis by regulating the ubiquitination or deubiquitination of lipid raft proteins.

Interestingly, loss of UCH-L1 enhanced lipid raft-dependent en- docytosis and then, cell-to-cell transmission of $\alpha$-synuclein. Prionlike propagation of protein inclusions such as $\alpha$-synuclein, tau, and mutant huntingtin in many neurodegenerative diseases has received a great deal of attention. Although the detailed mechanism of intercellular propagation of protein inclusions has not been well understood, this propagation has been anticipated to explain the unveiled pathogenesis of many neurodegenerative diseases [25]. Given that the molecular pathways of neurodegeneration triggered by each mutation may be shared by several genetic forms of PD, it is unsurprising that many PD-related genes have been shown to affect one or more of these processes. Loss of parkin has been reported to be involved in lipid rafts-dependent endocytosis and cell-to-cell transmission of $\alpha$-synuclein [27]. Glucocerebrosidase depletion, which is strongly associated with PD, promotes propagation of $\alpha$-synuclein aggregates [53]. The knock-down of some orthologs of some PD-related genes such as catp-6 (ATP13A2), djr-1.2 (DJ-1), lrk-1 (LRRK2), pdr-1 (Parkin) has been also reported to increase cell-to-cell transmission of $\alpha$-synuclein in a C. elegans BiFC model [54].

Decreased UCH-L1 expression and oxidative modification of $\mathrm{UCH}-\mathrm{L} 1$ have been observed in the brains of $\mathrm{AD}$ and $\mathrm{PD}$ patients [3]. The overexpression of UCH-L1 reduces the number of amyloid beta plaques and improves memory deficits in AD mice [55], suggesting that $\mathrm{UCH}-\mathrm{L} 1$ has a protective effect in $\mathrm{AD}$ models. Accordingly, enhancing UCH-L1 activity may become a useful target against $\mathrm{AD}$ and $\mathrm{PD}$ progression.

In summary, we demonstrated that UCH-L1 associates with lipid rafts in the same way as other PD-associated gene products, and also that UCH-L1 regulates lipid raft-dependent endocytosis and cell-to-cell transmission of alpha-synuclein. This study provides more evidence that many $\mathrm{PD}$-associated gene products share common signaling pathways to explain the pathogenesis of $\mathrm{PD}$ and evidence of UCH-L1 activity as a useful target against the progression of $\mathrm{PD}$.

\section{ACKNOWLEDGEMENTS}

The authors thank Dr. K. J. Lee (Graduate School of Pharmaceutical Sciences, College of Pharmacy, Ewha Womans University, Seoul, Korea) for providing plasmids for UCH-L1-myc. This research was supported by the National Research Foundation of Korea (NRF) grants funded by the Korean government (Ministry of Science and ICT) (Grant No. 2017R1E1A1A91973713, NRF2012R1A5A2048183). 


\section{REFERENCES}

1. Bishop P, Rocca D, Henley JM (2016) Ubiquitin C-terminal hydrolase L1 (UCH-L1): structure, distribution and roles in brain function and dysfunction. Biochem J 473:2453-2462.

2. Lowe J, McDermott H, Landon M, Mayer RJ, Wilkinson KD (1990) Ubiquitin carboxyl-terminal hydrolase (PGP 9.5) is selectively present in ubiquitinated inclusion bodies characteristic of human neurodegenerative diseases. J Pathol 161:153-160.

3. Choi J, Levey AI, Weintraub ST, Rees HD, Gearing M, Chin LS, Li L (2004) Oxidative modifications and down-regulation of ubiquitin carboxyl-terminal hydrolase L1 associated with idiopathic Parkinson's and Alzheimer's diseases. J Biol Chem 279:13256-13264.

4. Leroy E, Boyer R, Auburger G, Leube B, Ulm G, Mezey E, Harta G, Brownstein MJ, Jonnalagada S, Chernova T, Dehejia A, Lavedan C, Gasser T, Steinbach PJ, Wilkinson KD, Polymeropoulos MH (1998) The ubiquitin pathway in Parkinson's disease. Nature 395:451-452.

5. Maraganore DM, Farrer MJ, Hardy JA, Lincoln SJ, McDonnell SK, Rocca WA (1999) Case-control study of the ubiquitin carboxy-terminal hydrolase L1 gene in Parkinson's disease. Neurology 53:1858-1860.

6. Lincoln S, Vaughan J, Wood N, Baker M, Adamson J, GwinnHardy K, Lynch T, Hardy J, Farrer M (1999) Low frequency of pathogenic mutations in the ubiquitin carboxy-terminal hydrolase gene in familial Parkinson's disease. Neuroreport 10:427-429.

7. Zhu R, Zhu Y, Liu X, He Z (2014) UCH-L1 S18Y variant and risk of Parkinson's disease in Asian populations: an updated meta-analysis. Neurodegener Dis 14:194-203.

8. Korade Z, Kenworthy AK (2008) Lipid rafts, cholesterol, and the brain. Neuropharmacology 55:1265-1273.

9. Marin R, Fabelo N, Fernández-Echevarría C, Canerina-Amaro A, Rodríguez-Barreto D, Quinto-Alemany D, Mesa-Herrera F, Díaz M (2016) Lipid raft alterations in aged-associated neuropathologies. Curr Alzheimer Res 13:973-984.

10. Schengrund CL (2010) Lipid rafts: keys to neurodegeneration. Brain Res Bull 82:7-17.

11. Zhai J, Ström AL, Kilty R, Venkatakrishnan P, White J, Everson WV, Smart EJ, Zhu H (2009) Proteomic characterization of lipid raft proteins in amyotrophic lateral sclerosis mouse spinal cord. FEBS J 276:3308-3323.

12. Chadwick W, Brenneman R, Martin B, Maudsley S (2010) Complex and multidimensional lipid raft alterations in a murine model of Alzheimer's disease. Int J Alzheimers Dis

\section{0:604792}

13. Rushworth JV, Hooper NM (2010) Lipid rafts: linking Alzheimer's amyloid- $\beta$ production, aggregation, and toxicity at neuronal membranes. Int J Alzheimers Dis 2011:603052.

14. Fortin DL, Troyer MD, Nakamura K, Kubo S, Anthony MD, Edwards RH (2004) Lipid rafts mediate the synaptic localization of alpha-synuclein. J Neurosci 24:6715-6723.

15. Valencia A, Reeves PB, Sapp E, Li X, Alexander J, Kegel KB, Chase K, Aronin N, DiFiglia M (2010) Mutant huntingtin and glycogen synthase kinase 3-beta accumulate in neuronal lipid rafts of a presymptomatic knock-in mouse model of Huntington's disease. J Neurosci Res 88:179-190.

16. Naslavsky N, Stein R, Yanai A, Friedlander G, Taraboulos A (1997) Characterization of detergent-insoluble complexes containing the cellular prion protein and its scrapie isoform. J Biol Chem 272:6324-6331.

17. Kalvodova L, Kahya N, Schwille P, Ehehalt R, Verkade P, Drechsel D, Simons K (2005) Lipids as modulators of proteolytic activity of BACE: involvement of cholesterol, glycosphingolipids, and anionic phospholipids in vitro. J Biol Chem 280:36815-36823.

18. Hur JY, Teranishi Y, Kihara T, Yamamoto NG, Inoue M, Hosia W, Hashimoto M, Winblad B, Frykman S, Tjernberg LO (2012) Identification of novel $\gamma$-secretase-associated proteins in detergent-resistant membranes from brain. J Biol Chem 287:11991-12005.

19. Wada S, Morishima-Kawashima M, Qi Y, Misono H, Shimada Y, Ohno-Iwashita Y, Ihara Y (2003) Gamma-secretase activity is present in rafts but is not cholesterol-dependent. Biochemistry 42:13977-13986.

20. Fallon L, Moreau F, Croft BG, Labib N, Gu WJ, Fon EA (2002) Parkin and CASK/LIN-2 associate via a PDZ-mediated interaction and are co-localized in lipid rafts and postsynaptic densities in brain. J Biol Chem 277:486-491.

21. Silvestri L, Caputo V, Bellacchio E, Atorino L, Dallapiccola B, Valente EM, Casari G (2005) Mitochondrial import and enzymatic activity of PINK1 mutants associated to recessive parkinsonism. Hum Mol Genet 14:3477-3492.

22. Kim KS, Kim JS, Park JY, Suh YH, Jou I, Joe EH, Park SM (2013) DJ-1 associates with lipid rafts by palmitoylation and regulates lipid rafts-dependent endocytosis in astrocytes. Hum Mol Genet 22:4805-4817.

23. Hatano T, Kubo S, Imai S, Maeda M, Ishikawa K, Mizuno Y, Hattori N (2007) Leucine-rich repeat kinase 2 associates with lipid rafts. Hum Mol Genet 16:678-690.

24. Lee SJ, Desplats P, Sigurdson C, Tsigelny I, Masliah E (2010) Cell-to-cell transmission of non-prion protein aggregates. 
Nat Rev Neurol 6:702-706.

25. Stopschinski BE, Diamond MI (2017) The prion model for progression and diversity of neurodegenerative diseases. Lancet Neurol 16:323-332.

26. Park JY, Kim KS, Lee SB, Ryu JS, Chung KC, Choo YK, Jou I, Kim J, Park SM (2009) On the mechanism of internalization of alpha-synuclein into microglia: roles of ganglioside GM1 and lipid raft. J Neurochem 110:400-411.

27. Cha SH, Choi YR, Heo CH, Kang SJ, Joe EH, Jou I, Kim HM, Park SM (2015) Loss of parkin promotes lipid rafts-dependent endocytosis through accumulating caveolin-1: implications for Parkinson's disease. Mol Neurodegener 10:63.

28. Chen J, Huang RY, Turko IV (2013) Mass spectrometry assessment of ubiquitin carboxyl-terminal hydrolase L1 partitioning between soluble and particulate brain homogenate fractions. Anal Chem 85:6011-6017.

29. Nagamine S, Kabuta T, Furuta A, Yamamoto K, Takahashi A, Wada K (2010) Deficiency of ubiquitin carboxy-terminal hydrolase-L1 (UCH-L1) leads to vulnerability to lipid peroxidation. Neurochem Int 57:102-110.

30. Liu Z, Meray RK, Grammatopoulos TN, Fredenburg RA, Cookson MR, Liu Y, Logan T, Lansbury PT Jr (2009) Membrane-associated farnesylated UCH-L1 promotes alphasynuclein neurotoxicity and is a therapeutic target for Parkinson's disease. Proc Natl Acad Sci U S A 106:4635-4640.

31. Choi YR, Kang SJ, Kim JM, Lee SJ, Jou I, Joe EH, Park SM (2015) Fc $\gamma R$ RIIB mediates the inhibitory effect of aggregated a-synuclein on microglial phagocytosis. Neurobiol Dis 83:9099.

32. Choi YR, Cha SH, Kang SJ, Kim JB, Jou I, Park SM (2018) Prion-like propagation of $\alpha$-synuclein is regulated by the Fc $\gamma$ RIIB-SHP-1/2 signaling pathway in neurons. Cell Reports 22:136-148.

33. Zlatkine P, Mehul B, Magee AI (1997) Retargeting of cytosolic proteins to the plasma membrane by the Lck protein tyrosine kinase dual acylation motif. J Cell Sci 110:673-679.

34. Zheng YZ, Berg KB, Foster LJ (2009) Mitochondria do not contain lipid rafts, and lipid rafts do not contain mitochondrial proteins. J Lipid Res 50:988-998.

35. Kim JM, Cha SH, Choi YR, Jou I, Joe EH, Park SM (2016) DJ-1 deficiency impairs glutamate uptake into astrocytes via the regulation of flotillin- 1 and caveolin- 1 expression. Sci Rep 6:28823.

36. Marks DL, Singh RD, Choudhury A, Wheatley CL, Pagano RE (2005) Use of fluorescent sphingolipid analogs to study lipid transport along the endocytic pathway. Methods 36:186195.
37. Singh RD, Puri V, Valiyaveettil JT, Marks DL, Bittman R, Pagano RE (2003) Selective caveolin-1-dependent endocytosis of glycosphingolipids. Mol Biol Cell 14:3254-3265.

38. Maxfield FR, McGraw TE (2004) Endocytic recycling. Nat Rev Mol Cell Biol 5:121-132.

39. Widera A, Norouziyan F, Shen WC (2003) Mechanisms of TfR-mediated transcytosis and sorting in epithelial cells and applications toward drug delivery. Adv Drug Deliv Rev 55:1439-1466.

40. Tan YY, Zhou HY, Wang ZQ, Chen SD (2008) Endoplasmic reticulum stress contributes to the cell death induced by UCH-L1 inhibitor. Mol Cell Biochem 318:109-115.

41. Martínez-Villarreal J, García Tardón N, Ibáñez I, Giménez C, Zafra F (2012) Cell surface turnover of the glutamate transporter GLT-1 is mediated by ubiquitination/deubiquitination. Glia 60:1356-1365.

42. Clark IE, Dodson MW, Jiang C, Cao JH, Huh JR, Seol JH, Yoo SJ, Hay BA, Guo M (2006) Drosophila pink1 is required for mitochondrial function and interacts genetically with parkin. Nature 441:1162-1166.

43. Park J, Lee SB, Lee S, Kim Y, Song S, Kim S, Bae E, Kim J, Shong M, Kim JM, Chung J (2006) Mitochondrial dysfunction in Drosophila PINK1 mutants is complemented by parkin. Nature 441:1157-1161.

44. Thomas KJ, McCoy MK, Blackinton J, Beilina A, van der Brug M, Sandebring A, Miller D, Maric D, Cedazo-Minguez A, Cookson MR (2011) DJ-1 acts in parallel to the PINK1/ parkin pathway to control mitochondrial function and autophagy. Hum Mol Genet 20:40-50.

45. Greggio E, Bisaglia M, Civiero L, Bubacco L (2011) Leucinerich repeat kinase 2 and alpha-synuclein: intersecting pathways in the pathogenesis of Parkinson's disease? Mol Neurodegener 6:6.

46. Kamp F, Exner N, Lutz AK, Wender N, Hegermann J, Brunner B, Nuscher B, Bartels T, Giese A, Beyer K, Eimer S, Winklhofer KF, Haass C (2010) Inhibition of mitochondrial fusion by $a$-synuclein is rescued by PINK1, Parkin and DJ-1. EMBO J 29:3571-3589.

47. Levental I, Lingwood D, Grzybek M, Coskun U, Simons K (2010) Palmitoylation regulates raft affinity for the majority of integral raft proteins. Proc Natl Acad Sci U S A 107:2205022054.

48. Zhang FL, Casey PJ (1996) Protein prenylation: molecular mechanisms and functional consequences. Annu Rev Biochem 65:241-269.

49. Lerner EC, Qian Y, Blaskovich MA, Fossum RD, Vogt A, Sun J, Cox AD, Der CJ, Hamilton AD, Sebti SM (1995) Ras CAAX 
peptidomimetic FTI-277 selectively blocks oncogenic Ras signaling by inducing cytoplasmic accumulation of inactive Ras-Raf complexes. J Biol Chem 270:26802-26806.

50. Bishop P, Rubin P, Thomson AR, Rocca D, Henley JM (2014) The ubiquitin C-terminal hydrolase L1 (UCH-L1) C terminus plays a key role in protein stability, but its farnesylation is not required for membrane association in primary neurons. J Biol Chem 289:36140-36149.

51. Prior IA, Harding A, Yan J, Sluimer J, Parton RG, Hancock JF (2001) GTP-dependent segregation of H-ras from lipid rafts is required for biological activity. Nat Cell Biol 3:368-375.

52. Sigismund S, Woelk T, Puri C, Maspero E, Tacchetti C, Transidico P, Di Fiore PP, Polo S (2005) Clathrin-independent endocytosis of ubiquitinated cargos. Proc Natl Acad Sci U S A
102:2760-2765.

53. Bae EJ, Yang NY, Song M, Lee CS, Lee JS, Jung BC, Lee HJ, Kim S, Masliah E, Sardi SP, Lee SJ (2014) Glucocerebrosidase depletion enhances cell-to-cell transmission of $\alpha$-synuclein. Nat Commun 5:4755.

54. Tyson T, Senchuk M, Cooper JF, George S, Van Raamsdonk JM, Brundin P (2017) Novel animal model defines genetic contributions for neuron-to-neuron transfer of $\alpha$-synuclein. Sci Rep 7:7506.

55. Gong B, Cao Z, Zheng P, Vitolo OV, Liu S, Staniszewski A, Moolman D, Zhang H, Shelanski M, Arancio O (2006) Ubiquitin hydrolase Uch-L1 rescues beta-amyloid-induced decreases in synaptic function and contextual memory. Cell 126:775-788. 